\title{
Operational energy footprint of vehicle
}

ARTICLE INFO

Received: 11 June 2021

Revised: 13 July 2021

Accepted: 16 July 2021

Available online: 25 July 2021
One of the many important challenges of the modern world is the greenhouse effect of $\mathrm{CO}_{2}$. It is necessary to implement solutions that will eliminate it. Since the easiest way to eliminate the greenhouse effect is to reduce hydrocarbons fuel consumption, it is important to evaluate the fuel (energy) consumption in long term operation. The article presents a proposal for the use of the so-called vehicle energy footprint. The method of creating such a trace is presented and illustrated with specific results of data analyzes. The data is publicly available, which means that the presented method can be independently verified. It has also been shown that the use of the method not only organizes the analyzes, but also leads to information that cannot be obtained with other methods. It therefore seems that an attractive tool has been developed for future applications.

Key words: transport, vehicle, energy, consumption, long-term, footprint

This is an open access article under the CC BY license (http://creativecommons.org/licenses/BY/4.0/)

\section{Introduction}

The current challenge of the world economy is to become $\mathrm{CO}_{2}$ neutral. One of the most important branches of the economy is transport. It is estimated that $\mathrm{CO}_{2}$ emissions from transport account for about $17 \%$ of the total anthropogenic emissions. It may not seem like much, but each solution to reduction in emissions is worth noting. An additional factor concerning transport is the fact that a large part of transport emissions is generated in densely built-up areas, therefore the nuisance of these emissions is much greater than it would appear from the average data only. It is a matter of fact that $\mathrm{CO}_{2}$ emissions are accompanied by the emission of a whole host of toxic components in exhaust gases. They take all this into account reducing emissions from transport is a priority task.

The simplest solution to the problem of $\mathrm{CO}_{2}$ emissions would be to abandon the use of carbon or hydrocarbon energy carriers. It is an obvious solution, but difficult to implement in the relatively short period of several years that we have left to achieve equilibrium in the $\mathrm{CO}_{2}$ economy. If we focus on transport, then a solution that can be used in the socalled in the meantime, there is a reduction in the consumption of energy achieving from fuels, especially hydrocarbons. In other words, we need to cut the fuel consumption. There is nothing innovative in this statement, everyone knows it, but in the same time there is no satisfactory progress in achieving of fuel economy. The question is why? Of course, as usual, there are many reasons, but one of them is important in the author's opinion. It results from the fact that we conclude about the fuel consumption during long-term operation of, for example, vehicles, on the basis of the results of relatively short-term tests performed before the vehicles are put into operation.

The result is obvious. Fuel consumption in "natural" operation is far from that determined in short-term tests [1]. There is no shortage of evidence that this is the case, and the primary one is that the NEDC test has been changed to WLTP [1-3]. It turns out that the change slightly improved the situation. However, it is still unsatisfactory. Hence the increasing use of the RDE test [4-6] or simulation [7]. This is indeed an emissions test $[8,9]$, but can also be used to evaluate fuel consumption. But there is also the "other side of the coin". It is known that discrepancies between the results of fuel consumption in everyday use and what is given as a result, eg. WLTP, exist, but it is difficult to find publications in which these differences would be described. This, in turn, is due to the fact that the methods and procedures for assessing fuel (and more broadly, energy) consumption in the long-term operation of vehicles have not been implemented.

This paper may be useful in solving this problem. Based on the theory of cumulative fuel (energy) consumption developed by the author [10-13]. it shows the so-called fuel (energy) footprint of the vehicle in its long-term operation.

Analyzed is the fuel need for mileage in thousands of kilometers over a period of several years. That is in opposite to short-term tests - such as WLTP and RDE, various specialist tests [14] or simulations [7].

If the fuel consumption of vehicles in long-term operation is analyzed, i.e. over years and thousands of kilometers of mileage, it is important which evaluation methods should be used. Typically, most used, factor for assessing of the fuel consumption of cars is a fuel economy (FE) expressed in $\mathrm{dm}^{3} / 100 \mathrm{~km}$ or MPG (miles per gallon).

By the assumptions that $F_{i}-i$-th refueling, $t_{d i}-$ mileage to $F_{i}$, then the fuel economy $(\mathrm{FE})$ can be expressed as:

$$
\mathrm{FE}_{\mathrm{i}}=100 \mathrm{~F}_{\mathrm{i}}\left(\mathrm{t}_{\mathrm{di}}-\mathrm{t}_{\mathrm{di}-1}\right)
$$

By $n$ refueling can the average fuel economy (AEE) as

$$
\mathrm{AFE}_{\mathrm{n}}=\frac{1}{\mathrm{n}} \sum_{\mathrm{i}=1}^{\mathrm{n}} \mathrm{FE}_{\mathrm{i}}
$$

An example of FE and AFE values are given in Fig. 1.

The operational data of the vehicles presented in Fig. 1 come from the website spritmonitor.de. This data [15] was specially selected because it is widely available. In addition, the data of LEXUS GS 450h cars were selected for further analysis, as GS cars ceased to be produced in 2019, but are still in service. The data are publicly available for car with given code number. (as for example on Fig. 1). 


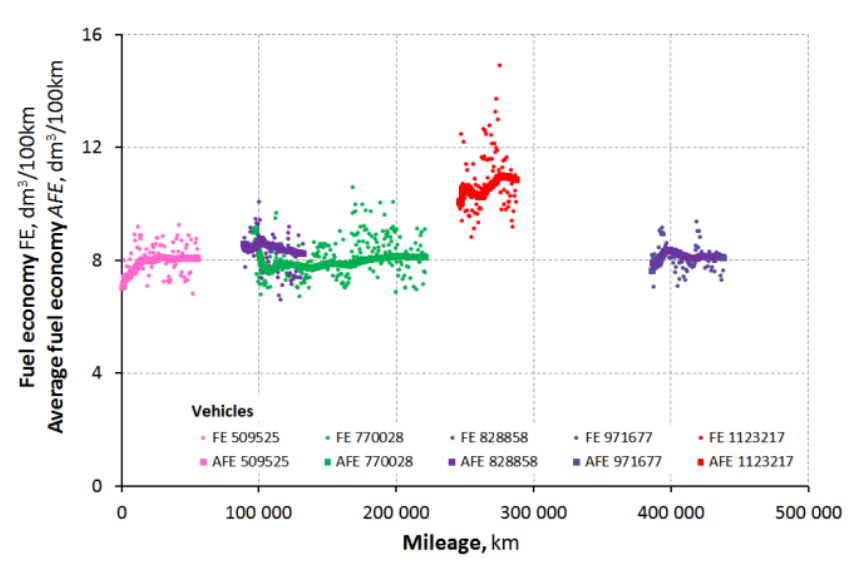

Fig. 1. A typical vehicles fuel economy between refueling (HEV LEXUS GS 450h)

From the database, those cars were selected, the data of which covers both the beginning of operation and those with relatively high mileage. Detailed information is presented further in Table 1.

When analyzing the presented data, it is difficult to draw any broader conclusions. It seems that other, more advanced evaluation methods need to be used. One of such methods is the method of building the vehicle's energy footprint, based on the theory of cumulative fuel (energy) consumption.

\section{Theory of cumulative fuel consumption}

Cumulative fuel consumption CFC to the achieve of mileage $t_{\mathrm{dn}}$, after many transformations, described in detail in [10], can be presented as a relationship

$$
\operatorname{CFCc}\left(t_{d}\right)=c t_{d}^{a+1}
$$

where: $c, a-$ constants, $t_{d}-$ the mileage.

Derivative of the cumulative energy consumption based on the vehicle engine run time " $t_{d}$ " is the intensity of the cumulative fuel consumption.

$$
\operatorname{ICFC}\left(t_{d}\right)=\frac{d C F C\left(t_{d}\right)}{d t_{d}}=c(a+1) t_{d}^{a}
$$

By $t_{d}=0$ the ICFC not exist.

To analyze of specific cumulative fuel consumption SCFC (similar to the AFE) exists a new relationship

$$
\operatorname{SCFC}\left(t_{d}\right)=\frac{\operatorname{CFC}\left(t_{d}\right)}{t_{d}}=c t_{d}^{a}
$$

The SCFC $\left(t_{d}\right)$ is expressed in $\mathrm{dm}^{3} / \mathrm{km}$.

Constants „c" and ,a” can be derived from the data obtained from the use of vehicles in natural operation.

\section{Results and Discussion}

The data for five HEVs were used for further analysis to determine the energy footprint of each analyzed vehicle. The results of these analysis are presented in Table 1.

As it can be see, the operational data, for each car, comes from the mileage of over tens of thousands of kilometers traveled over a period of several years. The data are recorded "until the last minute" and are up-to-date. The number of refueling is also relatively high. The largest is in the case of the vehicle number 770028 and in following more attention will be given to this data.
Table 1. Operational data and calculation results of the analyzed cars
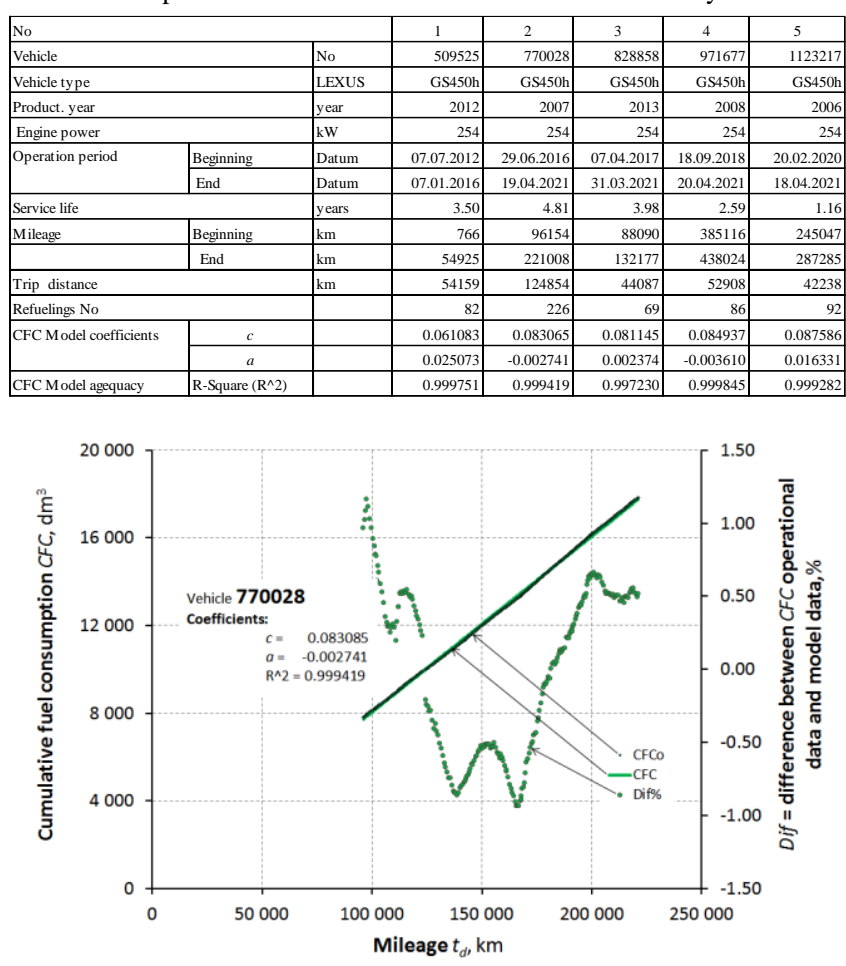

Fig. 2. Cumulative fuel consumption of vehicle nr 770028

The difference between the values of cumulative fuel consumption from operation and those determined using model (3) is not large (it does not exceed 1.5\%). It is important, however, that this difference does not assume constant values. The course of the cumulative fuel consumption is quasi-linear but not a straight line. The correlation coefficient of the math model $\mathrm{R}^{2}$ is greater than 0.999 which is an excellent value.

With the coefficients $c$ and $a$ of the mathematical model (3), the energy footprint of the vehicle can be presented. This trace consists of dependencies (3) to (5) Fig. 3.

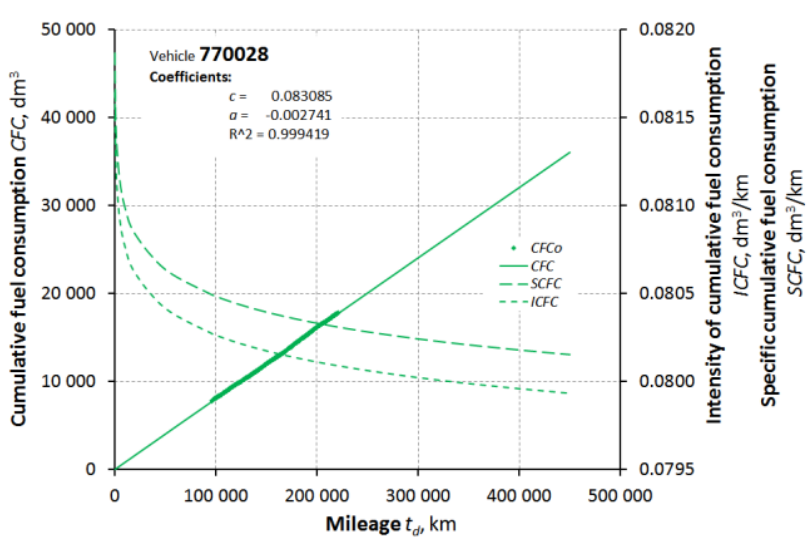

Fig. 3. Energy footprint of the vehicle 770028

The course of the cumulative fuel consumption is (in this case) quite unexpected. It is generally accepted that as mileage increases, the specific fuel consumption increases. The opposite is observed here. Multiplying the SCFC by 100 gives the equivalent of an AFE. The comparison of these values is shown in Fig. 4. 


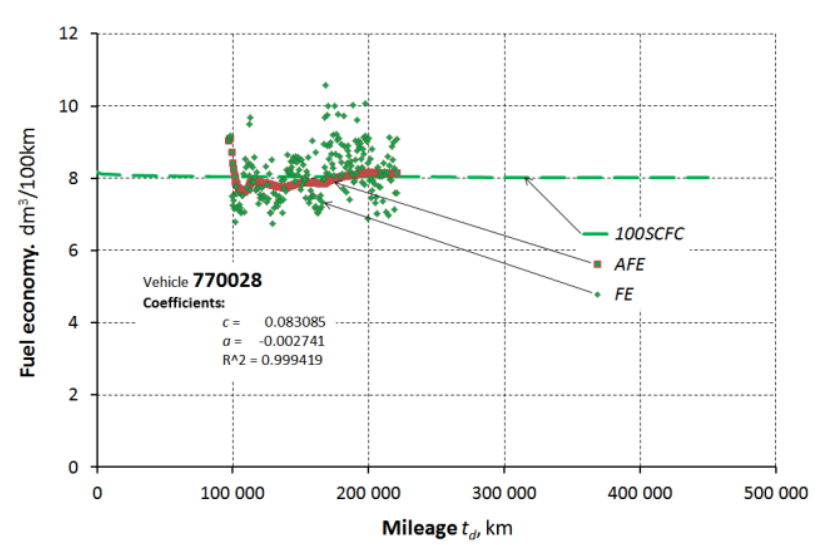

Fig. 4. Fuel economy of vehicle 770028

It seems that such an indicator as $100 \mathrm{SCFC}$ reflects the operational reality much more accurately than AFE.

The energy footprint can be presented for practically every vehicle, if, of course, the operational data are known. The basis is the determination of the $\mathrm{c}$ and a coefficients of the model (3). Figure 5 shows the cumulative fuel consumption curves of the vehicles listed in Table 1.

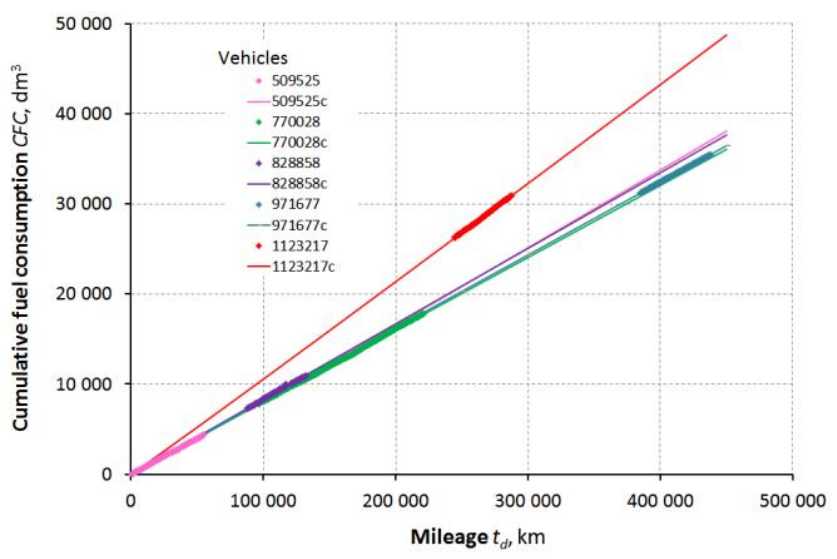

Fig. 5. Cumulative fuel consumptions of analyzed vehicles

It is clearly visible that the period of operation of the vehicle from which the operational data comes from is of little importance. This is confirmed by the deviation values of the model values from those observed in operation - Fig. 6 .

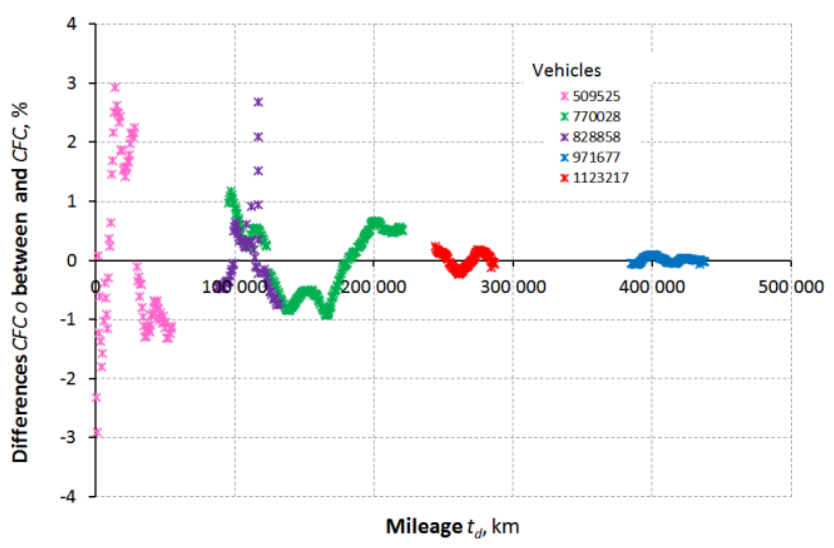

Fig. 6. Differences of CFC data from operation and calculation
The deviation values are small and appear to decrease with increasing mileage of the vehicle. This observation requires further analysis using data from a larger population of vehicles. If this were true, it would also mean that fuel consumption could be forecasted.

Figure 7 shows the courses of specific cumulated fuel consumption.

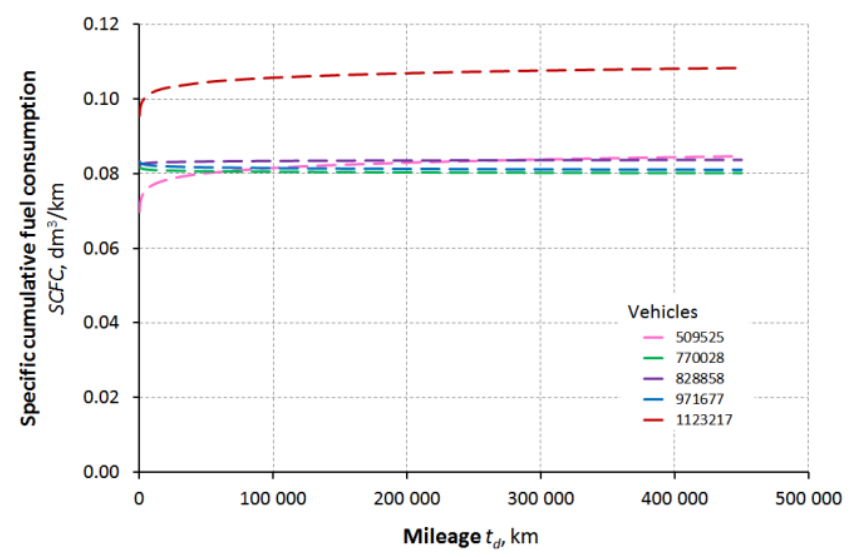

Fig. 7. Specific cumulative fuel consumption of analysed vehicles

The specific cumulative fuel consumption in some cases increases during the operation of the vehicle, and in others it decreases. It can also see that in some cases the SCFCs are almost identical (despite different trends) but there are also cases that differ significantly from others. The explanation why this is so is not the subject of this publication. It is worth saying here, however, that an analytical tool for this already exists.

\section{Summary}

One of the many important challenges of the modern world is to reduce the concentration of $\mathrm{CO}_{2}$ in the ambient air. Various activities are undertaken, including in the area of transport, which undoubtedly contribute to the greenhouse effect.

It is necessary to implement solutions that will eliminate this effect as soon as possible. However, the implementation of various solutions should be assessed in terms of their effectiveness. The only true assessment of the introduced changes concerns the day-to-day operation of vehicles. Since the easiest way to eliminate the greenhouse effect is to reduce fuel consumption, it is important to evaluate of really fuel consumption. The article presents a proposal for the use for this the so-called Vehicle energy footprint. The method of creating such a trace is presented and illustrated with specific results of data analyzes. The data is publicly available, which means that the presented method can be independently verified. It has also been shown that the use of the method not only organizes the analyzes, but also leads to information that cannot be obtained with other methods. It therefore seems that an attractive tool has been developed for future applications. 


\section{Nomenclature}

NEDC New European Driving Cycle

WLTP Worldwide Harmonized Light-Duty Vehicle Test

RDE Real Driving Emissions

F Fueling

FE Fuel Economy
AFE Average Fuel Economy

MPG Miles Per Gallon

CFC Cumulative Fuel Consumption

ICFC Intensity of Cumulative Fuel consumption

SCFC Specific Cumulative Fuel Consumption

\section{Bibliography}

[1] WELLER, K., LIPP, S., RÖCK, M. et al. Real world fuel consumption and emissions from LDVs and HDVs. Frontiers in Mechanical Engineering. 2019, 5, 45. https://doi.org/10.3389/fmech.2019.00045

[2] JANNSEN, N., KALLWEIT, M. Effects of the new WLTP test procedure. Wirtschaftsdienst. 2018, 98, 831-832. https://doi.org/10.1007/s10273-018-2374-8

[3] KORPACH, A.O., KORPACH, O.A. Worldwide Harmonized Light Vehicles Test Procedures (WLTP), Bulletin of the National Transport University. 2019, 1(43), 76-83. https://doi.org/10.33744/2308-6645-2019-1-43-076-083

[4] KURTYKA, K., PIELECHA, J. The evaluation of exhaust emission in RDE tests including dynamic driving conditions. Transportation Research Procedia. 2019, 40, 338-345. https://doi.org/10.1016/j.trpro.2019.07.050

[5] YAN, F., WANG, Y., ZHENG, S. et al. Research on the correlation between test cycles and RDE test. In: SUGUMARAN, V., XU, Z., ZHOU, H. (eds) Application of intelligent systems in multi-modal information analytics. MMIA 2019. Advances in Intelligent Systems and Computing. 2019, 929. Springer, Cham. https://doi.org/10.1007/978-3-030-15740-1_146

[6] TRIANTAFYLlOPOULOS, G., DIMARATOS, A., NTZIACHRISTOS, L. et al. A study on the $\mathrm{CO} 2$ and NOx emissions performance of Euro 6 diesel vehicles under various chassis dynamometer and on-road conditions including latest regulatory provisions. Science of the Total Environment. 2019. 666, 337-346.

https://doi.org/10.1016/j.scitotenv.2019.02.144

[7] AHN, K., RAKHA, H.A. A simple hybrid electric vehicle fuel consumption model for transportation applications. Applied Electromechanical Devices and Machines for Electric Mobility Solutions. 2019.

https://doi.org/10.5772/intechopen.89055

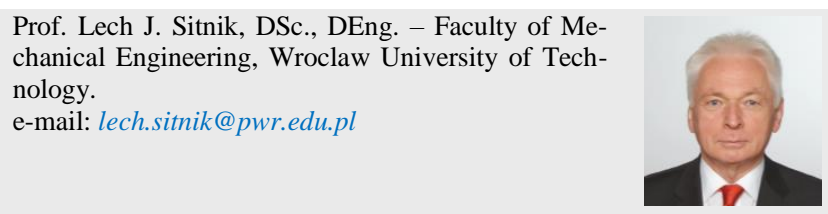

Prof. Lech J. Sitnik, DSc., DEng. - Faculty of Me-
chanical Engineering, Wroclaw University of Tech-
nology.
e-mail: lech.sitnik@pwr.edu.pl

[8] ZIOLKOWSKI, A., DASZKIEWICZ, P., RYMANIAK, L. et al. Analysis of the exhaust emissions from hybrid vehicle during RDE test. MATEC Web of Conferences. 2019, 294, 02002. https://doi.org/10.1051/matecconf/201929402002

[9] KURTYKA, K., PIELECHA, J., MERKISZ, J. The evaluation of $\mathrm{NO}_{\mathrm{x}}$ emissions in RDE tests including dynamic driving conditions. IOP Conference Series: Earth and Environmental Science. 2021, 642, 012017.

https://doi.org/10.1088/1755-1315/642/1/012017

[10] SITNIK, L.J. Cumulated fuel consumption. The Archives of Automotive Engineering - Archiwum Motoryzacji. 2004, 7(3), 227-254.

[11] SITNIK, L.J. Cumulated LPG consumption suplied of cars engines. Journal of KONES. 2009, 16(4), 429-434. yadda.icm.edu.pl/yadda/element/bwmeta1.element.baztecharticle-BUJ5-0033-0086

[12] SITNIK, L.J., Energy demand assessment for long term operation of vehicles. SAE Technical Paper 2020-01-2165. 2020. https://doi.org/10.4271/2020-01-2165

[13] SITNIK, L.J., IVANOV, Z.D., SROKA, Z.J. Energy demand assessment for long term operation of hybrid electric vehicles. IOP Conference Series: Materials Science and Engineering. 2020, 1002, 012026. https://doi.org/10.1088/1757-899X/1002/1/012026

[14] ALBIG, J. Keynote Lectures II - Test procedure at auto motor und sport - from A to Z. In: PFEFFER, P. (eds) 7th International Munich Chassis Symposium 2016. Proceedings. Springer Vieweg, Wiesbaden. https://doi.org/10.1007/978-3-658-14219-3_6

[15] Spritmonitor. Verbrauchswerte real erfahren. www.spritmonitor.de (accessed 2 June 2021) 